\title{
RECLAMACIONES TRANSFRONTERIZAS EN MATERIA CONTRACTUAL CONTRA TERCEROS AJENOS AL CONTRATO Y VIAJES COMBINADOS: LA SENTENCIA DEL TJUE 26 DE MARZO 2020, LIBUŠE KRÁLOVÁ VS. PRIMERA AIR SCANDINAVIA A/S (C-215/18): PLEASE MIND THE GAP BETWEEN THE PASSENGER AND THE AIR COMPANY;
}

\author{
CROSS BORDER CLAIMS AGAINST THIRD PARTIES WITHOUT \\ A CONTRACT WITH THE CLAIMANT AND PACKAGE \\ TRAVELS; JUDGMENT OF THE CJEU, 26 MARCH 2020, LIBUŠE \\ KRÁLOVÁ VS. PRIMERA AIR SCANDINAVIA A/S (C-215/18): \\ PLEASE MIND THE GAP BETWEEN THE PASSENGER \\ AND THE AIR COMPANY;
}

\author{
Dra. Anna María Ruiz MarTín \\ Lecturer in Law \\ Abogada del ICAM
}

Recibido: 14.06.2020 / Aceptado: 01.05.2020

DOI: https://doi.org/10.20318/cdt.2020.5627

\begin{abstract}
Resumen: En la sentencia del Tribunal de Justicia de la Unión Europea (TJUE) que se analiza, el asunto C-215/08, el TJUE pone de relieve una vez más ante que foro de competencia judicial internacional del Reglamento Bruselas I/Ibis, los pasajeros afectados por el incumplimiento de los transportistas aéreos pueden interponer reclamaciones transfronterizas de compensación. Pero se pronuncia para aquellos casos en los que no media un contrato con la compañía aérea sino con un tercero. En este supuesto, la pasajera no celebró el contrato de vuelo de forma directa con el transportista. Lo hizo con una Agencia de viajes domiciliada en su mismo Estado miembro (República Checa). El TJUE también interpreta por las particularidades del caso, la relación del Reglamento Bruselas I con otras normas específicas en el sector del transporte aéreo y contratos de consumo, como la Directiva 90/314/CEE, sobre viajes combinados y el Reglamento (CE) n ${ }^{\circ} 261 / 2004$ sobre compensación y asistencia a pasajeros.

Palabras clave: obligación contractual, contrato, reclamaciones transfronterizas, compensación, lugar de cumplimiento, transporte aéreo, pasajeros, consumidores, viaje combinado, calificación, interpretación restrictiva-estricta, legitimación pasiva.
\end{abstract}

Abstract: In the case analysed, the Judgement of the Court of Justice of the European Union (CJEU), -C-215/08-the CJEU highlights, once again, the scope of application and principles that rule the different fora established in the Brussels Regulation/Brussels I bis Regulation related to consumers protection and contractual obligations, when the claimant is a passenger of an operating airline. By means of these fora, passengers which have been affected for an infringment committed by the air company that is usually based on a different Member State, might bring cross border actions so as to seek for compensation; however, the seize of a proper forum in these cases, it will depend on the characterization of the claim. In this case, the passenger did not celebrate the contract with the air company, but with 
a Travel Agency located on her same Member State (Czech Republic). With regard to the features of this case, the ECJ has also to take into consideration the Directive 90/314/CEE, on Package travel and Regulation (EC) $n^{0} 261 / 2004$, on compensation and assistance to passengers.

Keywords: matters relating to a contract, contract, cross-border claims, compensation, place of performance, consumers, air carriage, passengers, package travel, characterization, restrictive interpretation, locus standi (passive).

Sumario: I. Consideraciones previas en torno al litigio; II. Los hechos y las cuestiones prejudiciales: 1. Los hechos: 2. Las cuestiones prejudiciales. III. Aspectos de Competencia judicial internacional: 1. Primera cuestión prejudicial: De la calificación de la obligación como "prestación de servicios"; Presupuestos para la aplicación del foro especial de la obligación contractual: A. Identificar la obligación contractual y el lugar de cumplimiento ¿no el "contrato" ?: B. Los principios del foro especial de la obligación contractual; 2. Segunda cuestión prejudicial: El foro de protección especial en contratos de consumo y su no aplicación en el asunto: A. Las diferencias en los presupuestos de aplicación con el foro especial de la obligación contractual: B. Conceptos de "contrato de consumo", "consumidor" en el Reglamento Bruselas I bis y principios de aplicación; IV. Las cuestiones de Derecho sustantivo: 1. Tercera cuestión prejudicial: Relación entre los derechos establecidos en el Reglamento 261/2004, la Directiva 90/314/CEE y el Reglamento Bruselas I; 2. Opinión del TJUE sobre la tercera cuestión prejudicial: "todos para uno y uno para todos, pero con reservas"; V. Conclusiones.

\section{Consideraciones previas en torno al litigio}

1. Una de las cuestiones más complejas en materia de foros de protección especial de contratos celebrados por consumidores en el ámbito del Reglamento Bruselas I / Ibis, es la determinación de cuando existe una "relación contractual de consumo". Así como determinar cuando se puede considerar como "consumidor" a una persona que reclama indemnización al contratante o profesional ${ }^{1}$. Según los poco precisos conceptos europeos dados por el artículo 15 Reglamento Bruselas I (ahora el artículo 17 del Reglamento Bruselas Ibis)².

2. La complejidad debe relacionarse también con el estado actual del Derecho derivado de consumo de la Unión Europea. Este acervo de normas es per se, una de las materias más fragmentadas en el Derecho Institucional privado, que pueden dificultar en numerosos litigios transfronterizos la operación de la determinación del foro correcto. Aparte de la noción de "consumidor" de la que no existe en este Derecho derivado, como de la de "profesional", una interpretación uniforme ni el ámbito sustantivo del Derecho de consumo ni en el DIPr en general".

3. En relación con la enorme fragmentación y nociones dispersas en los instrumentos jurídicos que existen hoy en día, esto supone que hay que saber precisar, cuáles son las normas que pueden invo-

\footnotetext{
${ }^{1}$ Reglamento (CE) 44/2001 del Consejo de 22 de diciembre de 2000 relativo a la competencia judicial internacional, el reconocimiento y la ejecución de resoluciones judiciales en materia civil y mercantil, DOCE, L 12, de 16 de enero de 2000, pp. 1-23, derogado por el Reglamento (UE) 1215/2012, del Parlamento Europeo y del Consejo de 12 de diciembre de 2012 relativo a la competencia judicial, el reconocimiento y la ejecución de resoluciones judiciales en materia civil y mercantil (refundición), DOUE, L 351, de 20 de diciembre de 2012.

${ }^{2}$ Siendo extrapolable lo analizado para el Reglamento Bruselas I, al Reglamento Bruselas I bis; STJUE Renate Ilsinger c. Martin Dreschers, 14 de mayo de 2009, C-180/06 (ECLI:EU:C:2009:303), FD. 58.

3 J. VAlant, "Consumer protection in the EU", European Parliametary Research Service (EPRS), 2015, disponible en: ei.pitt.edu/96092/1/consumer.1.pdf, esp. p. 6 ; C. TwIGG-Flesner, A Cross-Border Only Regulation for Consumer Transactions in the EU: A Fresh Approach to EU Consmer Law, SpringerBrief, 2012, esp., pp. 1-77; Con críticas por esta situación que provoca mayor inseguridad jurídica al consumidor, especialmente en contratos de transporte de pasajeros, Z. S. TANG, Electronic Consumer Contracts in the Conflict of Law, $2^{\mathrm{a}}$ ed., Bloomsbury, 2015, p. 222; J. HILl, Cross Border Consumer Contracts, Oxford University Press, 2008, p. 126 y ss; de forma general, F. Esteban De LA Rosa, La protección de los consumidores en el mercado interior europeo, Comares, 2003, esp. pp. 153-176.
} 
carse de forma específica, -según el sector de consumo ante el que estemos- e interpretarlas correctamente para entablar las acciones pertinentes ante los tribunales adecuados ${ }^{4}$. En los litigios transfronterizos, para poder relacionarlo en concreto con el Reglamento Bruselas I/Ibis. Un Reglamento de corte general de normas procesales civiles internacionales (en materia civil y mercantil) donde estos contratos de viajes combinados y los de transporte aéreo de pasajeros son incluidos 5 .

4. En los contratos de transporte, -como los contratos de transporte aéreo-, la complejidad se incrementa por niveles. De un lado, los contratos de transporte entre pasajeros y transportistas fueron excluidos de estos foros de protección especial de contratos celebrados por consumidores. A pesar de tener la condición de ser contratos de adhesión derivados de la contratación en masa en su mayoría (i.e.: contratos de consumo $)^{6}$. De otro lado, el legislador europeo estableció una excepción a esta expresa exclusión. Los contratos de transporte que se incluyen en un pack de "viaje combinado" si se encuentran incluidos en este foro especial como contratos de consumo. Pero para demandar a las Agencias de viajes que venden el pack de "viaje combinado", no a los transportistas aéreos que han podido incumplir su obligación?.

5. Este aspecto es bastante interesante, en cuanto el pasajero ya no es considerado "consumidor" frente al transportista aéreo en contratos de transporte en general. Por ende, debe entenderse que según el Reglamento Bruselas I / Ibis, el pasajero, -por muy consumidor que pueda ser en el Derecho sustantivo de consumo-, no goza de una protección especial porque no se considera que el vuelo o contrato de transporte es un contrato de consumo tal como se debe entender en este Reglamento de DIPr ${ }^{8}$. En

\footnotetext{
${ }^{4}$ Inter alia, N. ReIch, Undertanding European Consumer Law, Intersentia, 2009; N. RzEPECKI, Droit de la consommation et théorie générale du contract, Université Aix Marseille, 2002; S. WeAtherill, EU Consumer Law and Policy, 2aed., Elgar European Law, 2013, esp. pp. 92-143, pp. 126 y ss; S. CÁmARA LAFuente, "La codificación del Derecho de consumo: ¿refundación o refundición?", Revista de Derecho Civil, Vol.2, № 1, 2015, pp. 105-151; I. Llorente San Segundo, "La adaptación de la normativa reguladora del Derecho de desistimientos a las exigencias de la Directiva 2011/83/UE sobre derechos de los consumidores", $C D T, 2013$, Vol.5, No2, pp. 371-397, esp. pp. 372-373; J. KINDL, "La contratación mediante formularios en el Derecho privado de consumo alemán", InDret, N³, 2007, pp. 2-18, esp. p. 4-8, disponible en: https:/indret.com/wp-content/ themes/indret/pdf/1327.pdf

${ }^{5}$ No obstante, este particular no fue puesto de relieve en el asunto Air Scandinavia; E. Alvárez Armas y M. Dechamps, "Le droit international privé et la protection des passagers : l'articulation des sources européennes et internationales ", $R E D C$, 2012, pp. 749-777.

${ }^{6}$ STJUE Jana Pretuchová c. FIBO Group Holdings Limited, de 3 octubre de 2019, C-208/18 (ECLI:EU:C:2019:285), FD. 48; J. VAlant, "Consumer protection in the...", loc.cit., esp. pp. 12-13; A. Hernández Rodríguez, "El contrato de transporte aéreo de pasajeros: algunas consideraciones de Competencia judicial internacional y Derecho aplicable", $C D T, V_{0} .3, \mathrm{~N}^{\circ} 1$, 2011, pp.179-194; X. MARINÊz De OliveIra, "El contrato de transporte de personas como contrato de adhesión", Direito e Democracia, Vol. 12, No1, 2011, pp. 153-158; A-L., Calvo Caravaca y J. Carrascosa González, Derecho Internacional Privado,

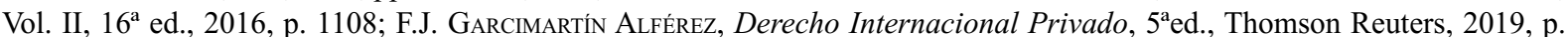
129; A. Arroyo Aparicio, "Capítulo II: Sección 4a: Artículo 17 y Artículo 18. Competencia en materia de contratos celebrados por los consumidores", en P. Blanco Morales Limones, F. F. Garau Sobrino M. L. Lorenzo Guillén y F. J. Montero Muriel (Coords.), Comentario al Reglamento (UE) No1215/2012 relativo a la competencia judicial, el reconocimiento y la ejecución de resoluciones judiciales en materia civil y mercantil. Reglamento Bruselas I refundido, Thomson Reuters, 2016, pp. 435-466; CECU, "La protección del consumidor en el transporte aéreo", CECU (Confederación estatal de Consumidores y Usuarios), 2009, disponible en: https://cecu.es/publicaciones/INC09 transaereo.pdf : P. MAESTRE CASAS, "El pasajero aéreo desprotegido: Obstáculos a la tutela judicial en litigios transfronterizos por incumplimientos de las compañías aéreas (A propósito de la STJUE de 9 de julio 2009, Rehder, As. C-204/08)", CDT, Vol. 3, №2,2011, pp. 282-303; Z. S. TANG, Electronic Consumer Contracts in

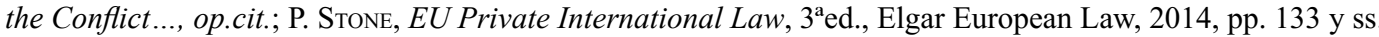

${ }^{7}$ Cf. art. 15 (3) del Reglamento Bruselas I (ahora art. 17 (3) del Reglamento Bruselas I bis): "La presente sección no se aplicará a los contratos de transporte, salvo el caso de los que, por un precio global, ofrecen una combinación de viaje y alojamiento" (la cursiva no es del original).

${ }^{8}$ Vid., v.gr., A. HeRnÁndeZ RodríGUEZ, "El contrato de transporte aéreo de pasajeros: algunas consideraciones de Competencia judicial internacional ...", loc.cit.; P. MAESTRE CASAS, "El pasajero aéreo desprotegido: Obstáculos a la tutela judicial en litigios transfronterizos por incumplimientos ...", loc.cit.; V. ANDREEVA ANDREEVA, "El pasajero no consumidor en el contrato international de transporte aéreo (Auto del TJUE de 13 de febrero de 2020), asunto C-606/19 de 2 de abril de 2020: C-271/14, Flighright GmbH vs. Iberia L.A.E., S.A. Operadora Unipersonal", Diario La Ley Unión Europea, № 81, 2020; J. C. FernánDEZ RozAs, "Competencia judicial especial en demanda de indemnización presentada contra el transportista aéreo encargado del último trayecto ante el órgano jurisdiccional en cuya demarcación se sitúa el punto de salida del primer trayecto (ATJ 13 febrero 2020)", Blog de José Carlos Fernández Rozas, 20/02/2020, disponible en: https://fernandezrozas.com/2020/02/20/
} 
los contratos de transporte excluidos del foro de protección especial, haya existido contrato o no entre el pasajero y la compañía aérea, el TJUE ha venido interpretando la "relación" contractual entre ambos, como una obligación de tipo contractual que puede considerarse como una "prestación de servicios".

En estos casos, -como consecuencia de lo anterior-, se aplica el foro especial por la razón de la materia de la obligación contractual. Un foro que opera desde la igualdad de condiciones entre las partes, como se explicará, por no tener el pasajero condición de consumidor, en el Reglamento Bruselas I/I bis. Una igualdad que a la luz de las normas del Derecho de consumo sobre la materia y en general, se puede considerar así mismo, una desigualdad. La justificación de esta exclusión y de esta solución, parece que se encuentra en la prevención de un forum actoris en este tipo de contratos de transportes ${ }^{10}$. Una solución que como han analizado previamente otros autores, emana de ciertos Informes explicativos oficiales de estas normas y que se asemeja a la que ofrece en particular, el Convenio de Montreal en materia de responsabilidad contractual del transportista aéreo ${ }^{11}$.

No obstante, en el asunto que se analiza, no se ponía el Reglamento Bruselas I/ I bis en relación con otros Convenios internacionales, sino con otros dos instrumentos jurídicos europeos específicos por razón de la materia del ámbito de los derechos de los pasajeros: la Directiva sobre viajes combinados (Directiva 90/314) ${ }^{12}$; y, el Reglamento sobre compensación y asistencia de pasajeros aéreos (Reglamento $261 / 2004)^{13}$.

6. Estas consideraciones previas son necesarias para realizar la operación de la calificación de la obligación que sirve de base a la demanda que posteriormente determinará la acción y la pretensión del demandante. Una calificación autónoma que debe hacerse de conformidad, -según reiterada jurisprudencia del TJUE-, con los conceptos europeos dados por los Reglamentos de DIPr patrimonial europeo $^{14}$. De otra parte, para determinar si el prestador del servicio que no ha celebrado un contrato con el

competencia-judicial-especial-en-demanda-de-indemnizacion-presentada-contra-el-transportista-aereo-encargado-del-ultimotrayecto-ante-el-organo-jurisdiccional-en-cuya-demarcacion-se-situa-el-punto-de/

${ }^{9}$ Vid., infra, Epígrafe III, apartado 1. A.

${ }^{10}$ Ibid. (Hernández Rodríguez) esp. p. 189 y nota 28, donde la autora cita el Informe Schlosser, que ofrece la explicación del porqué se excluyeron los contratos de transporte aéreo del foro de protección especial de contratos celebrados por consumidores (dado que el Reglamento Bruselas I bis, ni su informe explicativo lo justifican). Con acertadas críticas a esta exclusión en el INFORME SCHLOSSER.

${ }^{11}$ Instrumento de ratificación del Convenio para la unificación de ciertas reglas para el transporte aéreo internacional, hecho en Monreal, el 28 de mayo de 1999, BOE nº 122 de 20 de mayo de 2004; Ibid. (HernÁndez Rodríguez) p. 192; Z. S. TANG, Electronic Consumer Contracts in the ..., op.cit., pp. 221 y ss. La autora considera que la justificación estriba como estableció Schlosser, en evitar un conflicto entre las obligaciones de los instrumentos jurídicos de la Unión Europea y los tratados internacionales que se han hecho sobre la materia, como el Convenio de Montreal. No obstante, el mismo Reglamento Bruselas I bis en su Cdo. 35 ya establece la compatibilidad entre instrumentos jurídicos que siguen sin justificar, o al menos, explicar, dicha exclusión.

${ }_{12}$ En este supuesto se aplicó la Directiva 90/314, por su ámbito temporal; Directiva 90/314/CEE del Consejo, de 13 de junio de 1990, relativos a los viajes combinados, las vacaciones y los circuitos combinados, DOCE, $L 158$, de 23 de junio de 1990, pp. 59-64 sustituida por la Directiva 2015/2302; S.F. Álvarez Sotomayor, "El tratamiento legal del contrato de viaje combinado en el Derecho internacional privado", CDT, Vol. 4, N², 2012, pp. 123-139.

${ }^{13}$ Reglamento (CE) No 261/2004 del Parlamento Europeo y del Consejo, de 11 de febrero de 2004, por el que se establecen normas comunes sobre compensación y asistencia a los pasajeros aéreos en caso de denegación de embarque y de cancelación o gran retraso de vuelos, y se deroga el Reglamento (CEE) No 295/91, DOUE, no 46, de 14 de febrero de 2004, pp. 1-7.

${ }^{14}$ Algunos ejemplos de la ingente jurisprudencia que existe del TJUE sobre este particular: STJUE Industrie Tessili Italiana Como vs. Dunlop AG, de 6 de octubre de 1976, C-12/76 (ECLI:EU:C:1976:133); STJUE Car Trim GmhB c. KeySafety Systems Srl., 25 de febrero de 2010, C-381/08 (ECLI:EU:C:2010:90); STJUE STJUE Brogsitter c. Fabrication de Montres Normandes, 13 de marzo de 2014, C-548/12 (ECLI:EU:C:2014:148); Conclusiones del Abogado General Sr. Henrik Saugmandsgaard ØE, de 7 de noviembre de 2019, C-215/18, Libuše Králová c. Primera Air Scandinavia (ECLI:EU: C :2019:931), p. 31; A-L., CALvo CARAVACA y J. Carrascosa GonzÁlez, Derecho Internacional Privado, Vol. I, 16 ed., 2016, pp. 197-201; id. Derecho International..., vol. 1, op.cit, pp. 472-475 F.J. Garcimartín Alférez, Derecho Internacional..., op.cit., p. 103; M. A. Cérí́n Salvat, "Estrategia procesal y litigación transfronteriza: distinción entre la materia contractual y extracontractual", $C D T, 2014$, Vol. 6, №2, pp. 315-329; E. LeIN y A. Dickinson (ED.), The Brussels I Regulation Recast, Oxford University Press, 2015, pp.18-20; P. MANKOwSKY, "Article 7", en P. Mankowsky y H. Ullrich (eds.), European Commentaries on Private International Law, Brussels I bis Regulation (I Band), Ottosshmidt, 2016, p.198-ss; M. Minors, "Recherche sur la qualification en Droit international privé des obligations. Pour une unité de la qualification", RDIA, No 1, 2018, pp. 220-235; R. ARENAS GARCÍA, "La distinción entre obligaciones contractuales y extracontractuales en los instrumentos comunitarios de Derecho internacional privado", AEDIPr, t. IV, 2006, pp. 403-425. 
pasajero de forma directa tiene legitimidad pasiva o no. Y en base a qué normas del Derecho derivado tiene tal legitimidad pasiva. Algo que se determina por la lex causae o el derecho sustantivo que rige el fondo del asunto, no por las normas de competencia judicial internacional del Reglamento Bruselas I/I bis $^{15}$. Todas estas cuestiones son las que se analizan en esta contribución, a la luz del asunto, Libuše Králová v. Primera Air Scandinavia A/S, C-215/18, (en lo sucesivo, asunto Air Scandinavia) ${ }^{16}$.

\section{Los hechos y las cuestiones prejudiciales}

\section{Los hechos}

7. La sra. Králová, -ciudadana checa con domicilio en Praga (República Checa)-, interpuso acciones transfronterizas de compensación el 10 de octubre de 2013, en los tribunales checos (de su propio domicilio) contra una compañía aérea, -sociedad domiciliada en Dinamarca-, la compañía Primera Air Scandinavia ${ }^{17}$. El objeto de su demanda estaba fundamentado en el perjuicio causado por un retraso de cuatro horas que tuvo la compañía aérea, de un vuelo de Praga a Keflavik (Islandia) con fecha de 25 de abril de 2013, que la sra. Králová tenía que realizar, para llegar al destino que había contratado de vacaciones en Islandia. El viaje y el alojamiento habían sido contratados a través de una Agencia de viajes, -la sociedad FIRO-tour a. s.-, domiciliada también en la República Checa.

La representación procesal de la sra. Králová invocó el art. 16 del Reglamento Bruselas I (art. 18 en el Reglamento Bruselas I bis). Esto es, el foro de protección especial para contratos celebrados por consumidores, por entender que la condición de la sra. Králová frente a la del transportista aéreo era de consumidora. Sin embargo, no había demandado también a la Agencia de viajes a la vez que al transportista aéreo. Sobre el fondo del asunto, invoca el artículo 6 apartado 1 y 7 del Reglamento $n^{\circ}$ 261/2004 que concede el derecho a los pasajeros de interponer acciones de compensación en caso de retraso en sus vuelos. Como se desprendía de asuntos anteriores del TJUE. Entre estos, la STJUE Sturgeon y otros ${ }^{18}$.

8. El 1 de abril del 2014, el Tribunal del Distrito 8 de Praga se declara incompetente para conocer de la demanda planteada por la sra. Králová ${ }^{19}$. Fundamenta tal incompetencia procesal en dos razones.

${ }^{15}$ A-L., Calvo Caravaca y J. Carrascosa González, Derecho International ..., vol. I, op.cit, p. 167 y p. 865.

${ }^{16}$ Sentencia del TJUE (Sala Primera), Libuše Králová v. Primera Air Scandinavia A/S, de 26 de marzo de 2020, C-215/18 (ECLI:EU:C:2020:235); M. WeLLER, "Matters relating to a contract" without contract (with the claimant)-ECJ, Judgment of 26 March 2020, Case C-215/18, Libuše Králová v. Primera Air Scandinavia A/S, on Article 5 no.1 Brussels I Regulation”, Conflict of Laws, 5 de abril de 2020, disponible en: https://conflictoflaws.net/2020/matters-relating-to-a-contract-without-contract-ecjjudgment-of-26-march-2020-case-c-215-18-libuse-kralova-v-primera-air-scandinavia-a-s-on-article-5-no-1-brussels-i-r/

${ }^{17}$ Ante el Tribunal del Distrito 8 de Praga (Obvodní soud pro Prahu 8). De forma previa, en julio de ese año y sin éxito, la sra. Králová había solicitado extrajudicialmente a la compañía aérea la compensación a tanto alzado de 400 euros establecida en el Reglamento 261/2004. La compañía aérea se negó invocando las excepciones de este mismo Reglamento para el pago de la compensación, alegando que el retraso fue producido por circunstancias extraordinarias imprevisibles.

${ }_{18}$ Conclusiones del Abogado General, Sr. Henrik Saugmandsgaard ØE, p. 18; STJUE Sturgeon y otros, de 19 de noviembre de 2009, C-402/07 y C-432/07, (EU:C:2009:716). En Sturgeon y otros, el TJUE interpretó loa artículos 5, 6 y 7 del Reglamento $n^{\circ} 261 / 2004$ en el sentido que los pasajeros de los vuelos retrasados pueden equipararse a los pasajeros de los vuelos cancelados a los efectos de la aplicación del derecho a compensación. Con lo que pueden invocar el artículo 7 de dicho Reglamento cuando soportan una pérdida de tiempo igual o superior a tres horas de retraso; R. PAZOS CASTRO, "El derecho a compensación por retraso en la normativa europea de transporte aéreo de pasajeros", InDret, Vol. 2, 2017, pp 2-57, esp. pp. 14-19, donde el autor analiza de forma crítica la sentencia Sturgeon y otros.

${ }^{19}$ Aquí cabe recordar lo que apunta la Doctrina en relación con la calificación de la pretensión por el demandante. El tribunal no tiene que seguir lo que el demandante establece en su demanda, sino que deberá ser el mismo tribunal el que califique la pretensión del actor como proceda. En el mismo análisis por el tribunal de la calificación de la pretensión, el juez se podrá apartar de las pretensiones del demandante en caso de no considerar que son correctas a la luz de los instrumentos jurídicos invocados (como hizo en este asunto); A-L., Calvo Caravaca y J. Carrascosa González, Derecho International..., Vol. I, op.cit p. 169. Cómo recuerdan los autores, establecido de forma acertada por el TJUE en la STJUE Holterman Ferho Exploitative BV, Ferho Bewehreungsstahl GmbH y otros c. Friedrich Leopold Freiherr Spies von Büllenshein, de 10 de septiembre de 2015 , C-47/14 (ECLI:EU:C:2015:574) 
Primero, que el ámbito territorial del Reglamento Bruselas I excluye a los domiciliados en Dinamarca. Segundo, que las partes no estaban vinculadas por una relación contractual según este artículo, porque este tipo de contratos de transporte está excluido de forma expresa en el art. 15 apartado $3^{\circ}$ del Reglamento Bruselas I ${ }^{20}$. El 4 de agosto de 2014, el Tribunal Municipal de Praga (Mêstsky soudv. Praze) desestimó el recurso interpuesto por la sra. Králová, al considerar que el Reglamento Bruselas I debía aplicarse. Entiende que desde el año 2007, el ámbito territorial del Reglamento Bruselas I / Ibis si incluye a los demandados domiciliados en Dinamarca. Con relación al segundo motivo, considera como el tribunal de instancia, que los tribunales checos no podían declararse competentes por no entender comprendida la acción en el foro de protección especial, del art. 16 apar. 1 y tampoco del art. 15 apar. $3^{\circ}$ porque el demandando era el transportista y no la Agencia de viajes ${ }^{\circ}$.

9. En septiembre del año 2015, el Tribunal Supremo de la República Checa (Nejvyšši Soud) conoce en casación del recurso interpuesto por la sra. Králová. Anula todas las decisiones de primera instancia y apelación. Devuelve los autos al tribunal de Primera Instancia y le pide a este tribunal que reconsidere: "si la compañía danesa podía ser demandada en Praga, pero en base al foro especial por razón de la materia, según lo establecido en el artículo 5 apartado $1^{\circ}$ letra b, inciso segundo, del Reglamento Bruselas I". Para ello debía solicitar una cuestión prejudicial al TJUE ${ }^{21}$. Presentaron observaciones en el proceso, el Gobierno checo y la Comisión Europea. Cada uno de ellos alegando posiciones diferentes, especialmente en la aplicación del foro que debía aplicarse. El Abogado General, Sr. Henrik Saugmandsgaard ØE presentó sus conclusiones el 7 de noviembre de 2019.

\section{Las cuestiones prejudiciales}

10. En atención a estos hechos comentados en el apartado I.1., se planteó al TJUE por el órgano jurisdiccional checo, las siguientes cuestiones prejudiciales ${ }^{22}$ :

i) ¿Existe una obligación de tipo contractual entre la Sra. Králová como pasajera "consumidora" y el transportista aéreo danés, a efectos de poder entender que los tribunales checos tienen competencia judicial internacional según el artículo 5 del Reglamento Bruselas I?. En concreto, $¿$ en base a la letra b? Teniendo en cuenta que ambos litigantes, no celebraron ningún contrato, sino que fue firmado entre un tercero y la consumidora.

ii) ¿Podría calificarse esta relación entre un consumidor y un profesional con arreglo a la sección $4^{\mathrm{a}}$ del Capítulo II, de acuerdo con los artículos 15 y 16 del Reglamento Bruselas I, si se demanda también a la Agencia de viajes y atraer en este foro, al cocontratante del contratante en este tipo de contratos de transporte y viaje combinado?

iii) En relación con el Reglamento 261/2004 y con la Directiva 90/314, ¿tiene la demandada (Primera Air Scandinavia) legitimidad pasiva en esta acción, basada en el lugar del cumplimiento de la prestación del servicio, donde la consumidora no contrató de forma directa con el transportista aéreo y para interponer acciones de compensación?

${ }^{20}$ Conclusiones del Abogado General, Sr. Henrik Saugmandsgaard ØE, FD 19; Cdo. 41 del Reglamento Bruselas I bis; A-L. Calvo Caravaca y J. Carrascosa González, Derecho International..., Vol., 1 FD. 19, p. 204.

${ }^{21}$ Cdo. 11 del Reglamento Bruselas I; "Las reglas de competencia judicial deben presentar un alto grado de previsibilidad y deben fundamentarse en el principio de que la competencia judicial se basa generalmente en el domicilio del demandado y esta competencia debe regir siempre, excepto en algunos casos muy concretos en los que la materia en litigio o la autonomía de las partes justifique otro criterio de vinculación (...)” y Cdo. 15 del Reglamento Bruselas Ibis.

${ }^{22}$ Cdo. 21 y artículo 1, apar. $3^{\circ}$, del Reglamento Bruselas I; Acuerdo entre la Comunidad Europea y el Reino de Dinamarca relativo a la competencia judicial, el reconocimiento, y la ejecución de resoluciones en materia civil y mercantil, firmado en Bruselas el 19 de octubre de 2005, DO 2005, L 299, p. 62; STJUE 12 de septiembre de 2013, Sunico y otros, C-49/12 (EU: C:2013:545). 


\section{Aspectos de Competencia judicial internacional}

\section{Primera cuestión prejudicial. De la calificación de la obligación como "prestación de servicios". Presupuestos para la aplicación del foro especial de la obligación contractual:}

\section{A. Identificar la "obligación contractual” y el lugar de cumplimiento ¿no el contrato?}

11. En primer lugar, el foro que se analiza para este caso del art. 5/art. 7 del Reglamento Bruselas I / Ibis, es el establecido en su apartado $1^{\circ}$ pero la letra $\mathrm{b}$ inciso $2^{\circ}$. Destinado para las obligaciones de naturaleza contractual que pueden considerarse como una "prestación de servicios". Cómo ha venido interpretándose del contrato de transporte aéreo (excluido del foro de protección especial de contratos celebrados por consumidores ${ }^{23}$. Se atiende a que la elección de este foro es una solución "alternativa" al foro general del domicilio del demandado en el sistema del Reglamento Bruselas I / Ibis que se permite realizar al demandante ${ }^{24}$.

12. Destaca el TJUE, -como un dato relevante en el análisis de su jurisprudencia, - que para considerar la aplicación de este foro especial por razón de la materia en la generalidad de las obligaciones de tipo contractual, la norma del ex.art. 5 apar. $1^{\circ}$ (art. 7 , apar. $1^{\circ}$ ), debe basarse en la causa de la acción que se determina mediante la obligación que sirve de base a la demanda. Pero no se basa en la identidad de las partes demandante-demandado, o en la existencia de un contrato "celebrado" entre las mismas que determine esta posición ${ }^{25}$.

13. Todo ello según la interpretación que el TJUE ha venido realizando del concepto autónomo de materia contractual de este foro. Esta jurisprudencia establece que una "obligación de tipo contractual" puede no conllevar siempre la exigencia de la celebración de un contrato entre las partes en el procedimiento. Lo que se necesita es que exista una obligación libremente asumida entre las partes,

${ }^{23}$ STJUE Flighright $y$ otros, de 7 de marzo de 2018, C-274/16; C-447/16; C-448/16, (ECLI:EU:C:2018:160), FD. 67; M. Taeymans, Essential Texts on European Tourism Law, $2^{\mathrm{a} e d}$., Gompel \& Svacina, 2019, pp. T. C. Hartley, International Commercial Litigation: Text, Cases and Materials on Private International Law, Cambridge University Press, 2020, p. 59; Z. S. TANG, Electronic Consumer Contracts in the Conflict of ..., op.cit. A. HERnÁNDEZ RodríGUEZ, "El contrato de transporte aéreo de pasajeros: algunas consideraciones de Competencia judicial...", loc.cit...; P. MAESTRE CASAS, "El pasajero aéreo desprotegido: Obstáculos a la tutela judicial ..", loc.cit., p.293; P.A.De Miguel Asensio, "El lugar de la ejecución de los contratos de prestación de servicios como criterio atributivo de competencia", en J. J. Forner i Delaygua, C. GonzÁlez BeILfusS y R. VIÑas FARRER (COORDS.), Entre Bruselas y La Haya. Estudios sobre la unificación internacional y regional del Derecho internacional privado. Liber Amicorum Alegría Borrás, Marcial Pons, 2013, pp. 291-307, esp. p. 6 (ucm prints); P.STONE, EU Private International Law..., op.cit., pp. 87-90, a propósito de lo que el TJUE consideró en el as. Rehder sobre la aplicación de este foro a los contratos de transporte aéreo de pasajeros. De otro lado, si no se considerase como una prestación de servicios, entonces se aplicaría la letra "a" por la jerarquía que rige en las obligaciones de tipo contractual que este foro abarca, STJUE Falco Privatstiffung y Thomas Rabitsch c. Gisela Weller Lindhorst, de 23 de abril de 2009, C-533/07 (ECLI:EU:C:2009:257), FD. 16 (jerarquía de aplicación de las letras del artículo 5/7); E. Alvárez Armas, S. FrancQ y M. Dechamps, "L'actualité de l'Article 5.1 du Règlement Bruxelles I: Evaluation des premiers arrêts interprétatifs portant sur la disposition relative à la compétence judiciare internationale en matière contractuelle", Cahiers du CeDIE, Working Papers 2011/02, pp. 2-32, disponible en: https:// uclouvain.be/fr/instituts-recherche/juri/cedie.

${ }^{24}$ Justificado en el Cdo. 15 del Reglamento Bruselas I bis.

${ }^{25}$ STJUE Kerr, de 8 de mayo de 2019, C-25/18 (ECLI:EU:C:2019:376), en la que el TJUE interpreta la exigencia de la identificación de la obligación para poder activar al foro de la obligación contractual, sea en su regla general (a) o sus reglas especiales (b) (entre la que se incluye la "prestación de servicios"), y que esta identificación debe realizarse y determinarse por el lugar donde hubiere sido o debiere ser cumplida la obligación (loci executionis); J. ECHEBARRía Fernández, "Jurisdiction and Applicable Law to claims related to the payment of contributions to the budged of an association of property owners for the maintenance of the communal áreas of a building. Comment on the Judgment of the Court of Justice of the European Union of 8 May 2019, Brian Andrew Kerr v Pavlo Postnov and Natalia Postnova, C-25/18”, CDT, vol. 11 (2), 2019, pp. 583-591, esp. p. 586 (10); R. JAFFERALI, "Le réglement Bruxelles I dans la jurisprudence des cours suprêmes (2010-2012), Allemange, Belgique, France, Pays-Bas et Royaume Uni", T.B.H., Larcier, №5, 2013, pp. 357-350, esp. pp.364-368; J.I. PARedes Pérez, "Pluralidad de lugares de prestación de servicios en los contratos de transporte de personas y mercancías", CDT, Marzo 2019, vol. 11 (1), pp. 478-497, esp. p.483 (vid. nota a pié de página 20); en relación al Auto del 2020 (no la STJUE Flighright). 
que genere derechos y obligaciones para ambas. Una obligación de carácter contractual que pueda ser considerada libremente asumida por las partes, más allá de un acuerdo mutuo ${ }^{26}$.

14. Esta interpretación debe ser restrictiva o más bien "estricta" como apuntan CALVo CARAVACA y CARRASCosa GonzÁlez ${ }^{27}$. Tanto del concepto de "obligación contractual", del "lugar de ejecución/ cumplimiento" (place of performance) como del concepto amplio de "prestación de servicios"28. Y diferente a la que se hace en contratos "celebrados" por consumidores, que sí exige la celebración de un contrato ${ }^{29}$. A veces, entre las partes no ha existido un contrato como tal. Ni tampoco, aunque hayan celebrado un contrato, las partes han determinado con precisión del lugar o lugares del cumplimiento de la obligación que las vincula en las cláusulas de este. Esto no significa que no exista una obligación contractual, ni que no existan lugares de cumplimiento efectivos, donde deba cumplirse la obligación que sirve de base a la demanda ${ }^{30}$. Que es lo que viene a decir el TJUE en su jurisprudencia sobre la interpretación de los conceptos de este foro especial y aplicación en los casos que procede de obligaciones que pueden ser consideradas como contractuales.

15. Como también se analizó en Flighright y que el TJUE extrapola a Air Scandinavia, en los supuestos de transporte aéreo para entender que existe una "obligación libremente asumida por las partes", debe atenderse a lo establecido en el artículo 3 apartado 5 del Reglamento 261/2004. En estos supuestos intracomunitarios de infracciones de operadores aéreos frente a pasajeros, se usa este instrumento por ser la ley material que rige el fondo del asunto. En cuestiones relativas a la competencia judicial internacional y para saber si existe una obligación de naturaleza contractual entre ambas partes,

${ }^{26}$ STJUE Color Drack GmbH c. Lexx International Vertriebs GmbH, C-386/05 (ECLI:EU:C:2007:262); A-L., CALVo CAravaca y J. Carrascosa González, Derecho Internacional..., vol.II, op.cit.; A-L., Calvo Caravaca, J. Carrascosa González Y J.V.Almuní Cid, "Capítulo 1: contratos internacionales: Competencia judicial y ley aplicable", en M. YzQUIERDo Tolsada (DIR.), Contratos civiles, mercantiles, públicos laborales internacionales, t. XVI, Thomson Reuters Aranzadi, 2014; P.A.DE Miguel Asensio, "El lugar de la ejecución de los contratos de prestación de servicios comoen J. J. Forner i Delaygua, C. GonzÁlez BeIlfuss y R. Viñas FarRer (COORds.), Entre Bruselas y La Haya. Estudios sobre la unificación internacional y ...

${ }^{27}$ STJUE Air Scandinavia, FD. 41.

${ }^{28}$ Vid., infra, apartado B; Conclusiones del Abogado General, sr. Henrik Saugmandsgaard ØE, p. 31; por ejemplo, como lo destaca el TJUE en la STJUE Flighright y otros, de 7 de marzo de 2018, C-274/16; C-447/16; C-448/16, (ECLI:EU:C:2018:160); sobre la interpretación del artículo 7 apartado $1^{\circ}$ letra a, STJUE Feniks, de 8 de mayo de 2019, C-337/17, (ECLI:EU:C: 2018:805); sobre la prestación de servicios como un concepto amplio del RBI bis, A-L., Calvo Caravaca y J. Carrascosa GonzÁlez, Derecho International..., Vol. II, op.cit.,p. 855; ); P. Berloz, "La notion de fourniture de services au sens de l'article 5-1b) du règlement Bruxelles I », JDIP, No3, 2008, pp. 675-717 ; A. MARs, "Qualification du contrat de concession de "fourniture de services » au sens du règlement Bruxelles I », JADE (Journal d'Actualité des Droits Européennes), 2014, disponible en : https://revue-jade.eu/article/view/455; P.A.De Miguel AsEnsio, "El lugar de la ejecución de los contratos de prestación de servicios ...", loc.cit., en J. J. Forner i Delaygua, C. González Beilfuss y R. Viñas Farrer (coords.), Entre Bruselas y La Haya. Estudios sobre la unificación internacional y regional de..., op.cit., p. 10 (ucmprints); no sin críticas por parte de algunos autores, C. Oró Martínez, "El artículo 5.1.b del Reglamento Bruselas I: examen crítico de la jurisprudencia reciente del Tribunal de Justicia", Indret, Vol. 2, 2013, pp. 2-24, disponible en: https://indret.com/wp-content/themes/indret/pdf/980.pdf; otros autores han propuesto incluso reformar este foro en el que podría ser el Reglamento Bruselas I ter, F. CORNETTE, "La nécessaire modification ou suppression de 1'Article 7-1 du Réglement Bruxelles I bis relatif au for contractuel dans un futur Règlement Bruxelles I ter?", en E. GuInchard (DiR.), Le nouveau règlement Bruxelle I bis-Règlement nº1215/2012 du 12 décembre 2012 concernant la compétence judiciaire, la reconnaissance et l'exécution des décisions en matière civile et commerciale, Bruylant, 2014, pp. 335-361, esp. p. 361, citando los trabajos de Droz, el cual ha considerado que las soluciones que ofrece el TJUE en su jurisprudencia interpretando los conceptos autónomos de este foro, son de "bricolaje"; sobre la interpretación de los conceptos autónomos por el TJUE, S. SÁNCHEZ LoREnzo, "El principio de coherencia en el Derecho internacional privado", REDI, Vol. 70 , No2, 2018, pp. 17-46, esp. pp. 26-35; un análisis prolijo, crítico y actual, de la interpretación del "lugar de cumplimiento" tanto en cuestiones de ley aplicable como del foro de la obligación de tipo contractual, C. ОкоLі, Place of Performance: A Comparative Analysis, Bloomsbury publishing, 2020.

${ }^{29}$ Cf. STJUE Air Scandinavia, FD. 42 y 43; STJUE Jakob Handte \& Co., GmhB v. Traitements Mécano-chimiques des Surfaces $S A$, de 17 de junio de 1992, C-26/91 (ECLI:EU:C:1992:228); STJUE Somafer SA c. Saar Ferngas AG, de 22 de noviembre de 1978, C-33/78 (ECLI:EU:C:1978:205), FD 5; STJUE Austro Mechana, C-572/14 (ECLI:EU:C:2016:286), FD. 34; STJUE Česká sporitelna as v Feichter, de 14 de marzo de 2013, C-419/11 (EU:C:2013: 165); E. LeIN y A. DickINSON (ED.), The Brussels I Regulation..., op.cit., pp. 143-146 y pp. 148-152; sobre la noción de contrato en el DIPr europeo, M. VINCENT HeUZÉ, « La notion de contract en droit international privé », Travaux du Comité français de droit international privé, №13, 2000, pp 319-344.

30 A-L., Calvo Caravaca y J. Carrascosa González, Derecho International..., vol. II, op.cit., p. 857. 
en este artículo se reconoce que el transportista aéreo tendrá dicha obligación (lo que se considerará la "relación contractual") con el pasajero en cuanto: "esta disposición se aplicará a todo transportista encargado de realizar un vuelo que proporcione transporte a los pasajeros que partan de un aeropuerto situado en el territorio de un Estado miembro o con destino a él”.

16. En los mismos supuestos en donde no existe un contrato celebrado entre el pasajero y el transportista aéreo, el artículo 3 apartado 5 también precisa que existe dicha obligación de naturaleza contractual: "cuando un transportista aéreo encargado de efectuar un vuelo que no tenga contrato con el pasajero dé cumplimiento a las obligaciones en virtud del presente Reglamento, se considerará que lo hace en nombre de la persona que tiene un contrato con el pasajero" 31 .

El mero hecho que el art. 3 apartado 5 del Reglamento 261/2004 considere que el transportista actuará en nombre de la persona que tiene el contrato con el pasajero, es reconocer que existe de forma implícita dicha obligación contractual que le obliga frente a este prestatario del servicio ${ }^{32}$. Esto es, que en caso de incumplimiento de la obligación que emana de este instrumento jurídico, puede ser demandado ante el tribunal de este foro de competencia especial. Así mismo se entenderá que el transportista aéreo, a efectos del artículo 2 (b) del Reglamento 261/2004, es el "encargado de efectuar el vuelo", siendo entonces considerado como el prestador del servicio ${ }^{33}$. Algo que tendrá relevancia para determinar la legitimidad pasiva. Como se pondrá de relieve en el análisis de la tercera cuestión prejudicial ${ }^{34}$.

\section{B. Los principios del foro especial de la obligación contractual}

17. Según el TJUE, la interpretación de los conceptos autónomos debe hacerse de conformidad con los principios que rigen el sistema de foros del Reglamento Bruselas I / I bis. En estos foros de competencias especiales o alternativas al foro general rigen fundamentalmente el principio de proximidad y el de previsibilidad. Esto tiene que ser de esta forma para dar cumplimiento al "efecto útil" (effect utile) de este instrumento jurídico ${ }^{35}$. A través de esta interpretación restrictiva/estricta de los

${ }^{31} C f$. Art. 3, apartado $5^{\circ}$ del Reglamento 261/2004, esp. in fine; STJUE CS y otros c. České airolinie, de 11 de julio de 2019, C-502/18 (ECLI:EU:C:2019:604); sobre la particular naturaleza del contrato de transporte aéreo, Z. S. TANG, Electronic Consumer Contracts in the Conflict of..., op.cit. pp. 218 y ss; B. FERRER TAPIA, El contrato áereo de pasajeros: sujetos, estatuto y responsabilidad, Dykinson, 2013.

${ }^{32}$ En Flighright, el TJUE analizó el lugar del cumplimiento de la prestación del servicio en un vuelo de conexión, por un supuesto en el que se produjo un gran retraso entre el vuelo de conexión y el principal. Los pasajeros sólo habían contratado con una sola compañía ambos vuelos. Siendo la que cometió la infracción, precisamente, con la que no habían contratado el pack de vuelos completo; J.I. PAREDEs Pérez, "Pluralidad de lugares de prestación de servicios en los contratos de transporte de personas ....”, loc.cit.; STJUE Air Scandinavia, párr. 50 y 51; también se tuvo que determinar la relación entre co-contrantantes en este tipo de transporte y el lugar de cumplimiento de la prestación del servicio, como en Flighright, en STJUE Peter Rehder c. Air Baltic Corporation, 9 de julio de 2009, C-204/08 (ECLI:EU:C: 2009:439); A. Hernández Rodríguez, "El contrato de transporte aéreo de pasajeros: algunas consideraciones de Competencia judicial...", loc.cit., p. 191; STJUE Peter Rehder c. Air Baltic Corporation, 9 de julio de 2009, C-204/08 (ECLI:EU:C: 2009:439), FD. 35 y 57; P. STONE, EU Private International Law..., op.cit., pp. 88; M.C. lamberTve-Autrand, « Contrats de prestations touristiques et for de protection des consomatterus dans l'espace judiciaire européen-Excursion sur les terres du for de protection du consomatteur dans l'espace judiciarie européen en compagnie d'un voyageur de tourisme », En D. Guével, P. Roussel Galle y C. Lagarde, Mélanges offerts au professeur Pascale Bloch, Bruylant, 2016, pp. 381-397 ; P.A.De Miguel Asensio, "El lugar de la ejecución de los contratos de prestación de servicios ...", loc.cit., en J. J. Forner i Delaygua, C. González Beilfuss y R. Viñas Farrer (coords.), Entre Bruselas y La Haya. Estudios sobre la unificación internacional y regional de..., op.cit., p. 8 (ucmprints).

${ }^{33}$ Vid., infra, apartado IV. 2, sobre la tercera cuestión prejudicial; STJUE CS y otros c. České airolinie, de 11 de julio de 2019, C-502/18 (ECLI:EU:C:2019:604), FD. 20-23, esta disposición establece dos requisitos de tipo cumulativo para considerar al transportista aéreo como el prestador del servicio: la existencia de un vuelo y la existencia de un contrato, en su párr. 28, si el transportista aéreo no ha celebrado el contrato de forma directa con el pasajero, también se entiende que lo hace en nombre de aquél que contrató con el pasajero; también en, STJUE Wirth y otros, de 4 julio de 2018, C-532/17 (ECLI:EU:C:2018:527).

34 Vid.infra epígrafe IV.

${ }^{35}$ STJUE Somafer SA c. Saar Ferngas AG, de 22 de noviembre de 1978, C-33/78 (ECLI:EU:C:1978:205), FD 7; sobre la interpretación estricta que debe hacerse de estos foros, STJUE Granarolo SpA c. Ambrosi Emmi France SA, 14 de julio de 2016, C-196/15 (ECLI:EU:C:2016:559), FD 17; STJUE flyLal-Lithuanina Airlines c. Starptautiskā lidosta Rïga VAS y Air Baltic Corporation As, C-302/13 (ECLI:EU:C:2014:2319), FD 26; vid., por todos, A-L., Calvo Caravaca y J. Carrascosa González, 
conceptos autónomos de cada uno de los foros que existen en el Reglamento y como ya se mencionó con anterioridad ${ }^{36}$.

En los foros de competencias especiales y a pesar de su alternatividad con el foro general del domicilio del demandado, la interpretación restrictiva no se realiza en relación con el foro general. Se debe realizar en relación con que estos foros ofrezcan la posibilidad de litigar al demandante ante tribunales de un Estado miembro o varios diferentes al del domicilio del demandado por razones de buena administración de justicia y seguridad jurídica. Una respuesta que puede considerarse aparentemente neutra a la alternancia de estos foros, que siempre ofrece la jurisprudencia del TJUE ${ }^{37}$.

18. Como consecuencia se llega a determinar de forma adecuada cual es el "lugar de cumplimiento" (place of performance) de la obligación que sirve de base a la demanda y el tribunal que es competente ${ }^{38}$. Una determinación que no se hace entre la cercanía y/o proximidad del demandado y/o el demandante ante el tribunal/es. Con diferencia de como se estima la acción ante el tribunal del domicilio del demandado que no está basado en el principio de proximidad ${ }^{39}$. En estos foros la respuesta está y debe estar basada en los principios de proximidad y previsibilidad entre el litigio/los hechos y el tribunal que debe conocer ${ }^{40}$.

19. De esta forma se pretenden evitar varios fenómenos. Primero, la multiplicidad de tribunales "gratuita" (conocido también por todos, como el "bad" forum shopping). Un fenómeno y estrategia procesal posible en la aplicación de los "foros de ataque" o neutros, en cuanto permiten la elección por parte del demandante de varios tribunales que no tienen porque ser el más previsible para el demandado ${ }^{41}$. El de su domicilio. Aplicando los principios de proximidad y previsibilidad, la elección que se le obliga a hacer el demandante debe estar basada en la cercanía de los hechos entre el litigio y el tribunal. De esta forma, no se quiebra la seguridad jurídica y el efecto útil, así como la igualdad procesal entre ambos litigantes.

Segundo, con la limitación que la proximidad se determina entre el objeto del litigio, los hechos y el tribunal y no entre la identidad de las partes, se evita que se produzca el denostado forum actoris o favor laesi que está proscrito en estos foros especiales. A diferencia de su justificación en los foros de

Derecho International..., Vol. I, op.cit, pp.289-290; H. GAUdEMET TALlon, Compétence et exécution des jugements en Europe. Règlement 44/2001, Convention de Bruxelles (1968) et de Lugano (1988 et 2007), 4ªed., 1.GDJ, 2010.

${ }^{36}$ Vid., supra apartado III.1. A; Por ejemplo, STJUE Falco Privatstiffung y Thomas Rabitsch c. Gisela Weller Lindhorst, de23 de abril de 2009, C-533/07 (ECLI:EU:C:2009:257), FD. 34 y 37 ; STJUE Corman Collins S.A. c. La Maison du Whisky S.A., 19 de diciembre 2013, C-9/12 (ECLI:EU:C: 2013:860), FD. 42; STJUE Granarolo SpA c. Ambrosi Emmi France SA, 14 de julio de 2016, C-196/15 (ECLI:EU:C:2016:559); STJUE Peter Rehder c. Air Baltic Corporation, 9 de julio de 2009, C-204/08 (ECLI :EU:C: 2009:439.

${ }^{37}$ P. Mankowski, “Article 7...”, loc.cit., en P. Mankowsky y H. Ullrich (eds.), European Commentaries on Private.., op.cit., p.198 y ss.

${ }^{38}$ Cdo. 16 del Reglamento Bruselas I bis; "El foro general del domicilio del demandado debe completarse con otros foros alternativos a causa de la estrecha conexión existe entre el órgano jurisdiccional y el litigio para facilitar una buena administración de justifica. La existencia de una estrecha conexión debe garantizar la seguridad jurídica y evitar la posibilidad de que una persona sea demandada ante un órgano jurisdiccional de un Estado miembro que no hubiera podido prever razonablemente. (...)" (la cursiva no es del original); A-L., Calvo Caravaca y J. Carrascosa González, Derecho International..., Vol. II, op.cit.,p. 855, lo que se intenta evitar-como ponen de relieve los autores-, es que se aplique el inciso de la letra a y c del artículo $5 / 7$ RBI bis, que son de aplicación; P. FranzinA, "Struttura e funzionamento del foro europeo della materia contrattuale alla luce delle sentenze Car Trim e Wood Floor della Corte di giustizia", RDIPeP, Vol. 46, No 3, 2010, pp. 655-684; en la jurisprudencia, pueden verse, STJUE Somafer SA c. Saar Ferngas AG, de 22 de noviembre de 1978, C-33/78 (ECLI:EU:C:1978:205), FD 5; STJUE Wintersteiger AG c. Products 4 U Sondermaschinenbau GmbH, C-523/10 (ECLI:EU:C:2012:220), FD 18; STJUE Car Trim GmhB c. KeySafety Systems Srl., 25 de febrero de 2010, C-381/08 (ECLI:EU:C:2010:90), FD 5 y 58.

${ }^{39}$ F. Cornette, "La nécessaire modification ou suppression de l'Article 7-1...», loc.cit., en E. Guinchard (Dir.), Le nouveau règlement Bruxelle I bis-Règlement $n^{\circ} 1215 / 2012$ du ..., op.cit. supra, p. 360.

${ }^{40}$ Cdo. 12 del Reglamento Bruselas I: "El foro general del domicilio del demandado debe completarse con otros foros alternativos a causa del estrecho nexo existente entre el órgano jurisdiccional y el litigio (...)"; Cdo. 11 del Reglamento Bruselas I: "Las reglas de competencia deben presentar un alto grado de previsibilidad y deben fundamentarse en el principio de que la competencia judicial se basa generalmente en el domicilio del demandado y esta competencia debe regir siempre, excepto en algunos casos muy concretos (...)".

${ }^{41}$ Vid., P. Mankowsky, Research Handbook on the Brussels I bis..., op.cit., p.24; A-L., Calvo Caravaca y J. Carrascosa GonzÁLEz, Derecho Internacional..., Vol. 1, op.cit., pp. 288-299; F. Esteban De La Rosa, La protección de los consumidores en el mercado interior..., op.cit., esp. p. 168. 
protección especial para la parte débil. De nuevo, debe mantenerse que las partes estén y deban estar en igualdad de condiciones procesales ${ }^{42}$. Por ello, estos foros se consideran "neutros", en cuanto no se favorece como en los foros de protección especial a ninguna de las partes.

20. Con todo lo analizado en este apartado puede considerarse que los objetivos de proximidad y previsibilidad se cumplen en el asunto Air Scandinavia para aplicar este foro, como consideró el TJUE. Tanto el lugar de salida como el de llegada son foros previsibles/próximos para interponer una demanda por incumplimiento contra el transportista aéreo por el pasajero.

Previsibles para ambas partes ${ }^{43}$. Era previsible para la compañía aérea poder ser demandada ante un órgano jurisdiccional checo, porque el vuelo como el lugar de cumplimiento de la prestación del servicio se debía realizar desde la República Checa como el lugar de salida ${ }^{44}$. Así como también hubiera sido previsible que la sra. Králová, hubiese establecido la demanda ante el lugar de llegada (Islandia). Ambos tribunales además son próximos con los hechos ocurridos según lo dispuesto en el Reglamento 261/2004 y la jurisprudencia relacionada del TJUE, como por ejemplo, los as. Rehder y Flighright.

\section{Segunda cuestión prejudicial: El foro de protección especial en contratos de consumo y su no aplicación en el asunto}

\section{A. Las diferencias en los presupuestos de aplicación con el foro especial de la obligación contractual}

21. Hay que diferenciar, -como hace el TJUE-, dos escenarios posibles para determinar la aplicación o no del foro de protección especial ${ }^{45}$.

i) El consumidor que contrata directamente el vuelo con el transportista no puede invocar la protección de este foro por estar expresamente excluida del mismo ${ }^{46}$. Haya o no existido la celebración del contrato de transporte.

ii) En el supuesto que la pasajera hubiera demandado a la Agencia de viajes con la que contrató el viaje combinado, entonces sí podría haber activado su protección, dado que el art. 15 apar. $3^{\circ}$, si incluye los contratos de transporte que se han vendido como parte del pack viajes combinados. Interpretando el concepto de "viaje combinado" con el ofrecido por la Directiva 90/134 para solicitar la compensación que le debe la compañía aérea mediante la Agencia ${ }^{47}$. Sin embargo, este aspecto merece ciertas observaciones ${ }^{48}$.

\footnotetext{
${ }^{42}$ Cf. A-L., Calvo Caravaca y J. Carrascosa González, Derecho International..., Vol. I, op.cit, pp. 289-290.

43 STJUE flyLal-Lithuanina Airlines c. Starptautiskā lidosta Rïga VAS y Air Baltic Corporation As, C-302/13 (ECLI:EU:C:2014:2319), FD. 43 y 45; Z. S. TANG, Electronic Consumer Contracts in the Conflict of..., op.cit., p. 226: "Both the place of departure and the place of destination have close connection with the performance of the contract, and both are reasonably predictable by the passenger and the airline"; M. GEORGE Y J. HARRIS, "Rehder v Air Baltic Corp (C-204/08): Service Contracts, Carriage by Air and the Brussels I Regulation”, Law Quarterly Review, Vol. 30, Nº, pp. 5 y ss; P. MAESTRE CASAS, "El pasajero aéreo desprotegido: Obstáculos a la tutela judicial ..”, loc.cit.; A-L., Calvo Caravaca y J. Carrascosa GonzÁlez, Derecho International...,vol. II, op.cit., p. 857.

${ }^{44}$ Conclusiones del Abogado General, sr. Henrik Saugmandsgaard ØE, p. 37.

${ }^{45}$ Sobre la Segunda cuestión prejudicial, STJUE Air Scandinavia, FD. 54, 56, 57 y 58.

46 STJUE Air Scandinavia.

${ }^{47}$ Art. 2 apartado 1 Directiva 90/314; S.F. Álvarez Sotomayor, "El tratamiento legal del contrato de viaje combinado en el...", loc.cit., pp. 128 y 132; M.J. Castellanos Ruiz, "El foro de los consumidores: Comentarios a la sentencia del TJUE de 23 de diciembre de 2015, Rüdiger Hobohm c. Benedikt Kampik Ltd. \& Co. KG y otros, C-293/14", CDT, Octubre 2017, Vol. 9, No2, pp. 641-649, esp. sobre el contenido del artículo 15 apartado $3^{\circ}$ letra c (artículo 17.3.c RBI bis), pp. 645-646; STJUE Peter Pammer c. Reederei Karl Schlüter GmbH \& Co. KG y Hotel Alpenhof GesmbH c. Oliver Heller, de 7 de diciembre de 2010 (C-585/08 y C-144/09) (ECLI:EU:C:2010:740); P.A.De Miguel Asensio, "El asunto Pammer y el artículo 15 RBI", 7 /12/2010, disponible en: http://pedrodemiguelasensio.blogspot.com/2010/12/el-asunto-pammer-y-el-articulo-15-rbi.html ; id. "La tutela de los consumidores en el mercado global: evolución del marco normativo", Estudios sobre Consumo, № 85, 2008, pp. 23-44, disponible en: https://eprints.ucm.es/8407/2/ESTCONSUMO(85)2008.pdf

${ }^{48}$ Vid. infra, apartado IV; S.F. Álvarez Sotomayor, "El tratamiento legal del contrato de viaje combinado en el Derecho internacional..., loc.cit.
} 
22. A diferencia del foro especial de la obligación contractual, en donde no se exige la celebración de un contrato entre las partes para el establecimiento de la acción, el artículo 15 apartado $1^{\circ}$ (artículo 17 apartado $1^{\circ}$ ) sí exige que se haya contrato celebrado con la "otra parte contratante" del consumidor. Esto es, que es determinante que se haya celebrado un contrato con el consumidor, como se analiza en el siguiente apartado ${ }^{49}$.

Este requisito no puede ser interpretado de forma extensiva por los principios que rigen estos foros. Al contrario de como lo interpretó la Comisión Europea en sus observaciones sobre el caso, por ser un supuesto de viaje combinado ${ }^{50}$. Lo justifica también en los argumentos del TJUE esgrimidos en el asunto Maletic ${ }^{51}$.

Del lado contrario, tanto el gobierno de la República Checa como el Abogado general, consideran que la relación que mediaba entre la pasajera y el transportista aéreo no podía considerarse entendida como un "contrato de consumo" a efectos del Reglamento Bruselas I/I bis. Ni en supuestos de viaje combinado. Sólo porque la Directiva 90/314 permita que se demande al transportista mediante una demanda a la Agencia, algo que la pasajera no realizó.

23. Finalmente, el TJUE se acerca a lo que dice que el Abogado General y el gobierno $\operatorname{checo}^{52}$. Los argumentos en los que el TJUE se basó en el asunto Maletic no pueden ser extrapolados al asunto Air Scandinavia. No encuentran las mismas características. En el asunto Maletic el contrato que el consumidor había celebrado con ambos cocontratantes se hizo de forma indisociable para ambos cocontratantes del consumidor. De una forma tal que no permitía la diferenciación-disociación entre el contrato con un primero que le vende el servicio y el segundo que le ha de prestar dicho servicio contratado de antemano ${ }^{53}$.

\section{B. Conceptos de "contrato de consumo" y "consumidor" en el Reglamento Bruselas I bis y prin- cipios de aplicación}

24. Los foros que se establecen en esta Sección $4^{a}$ título III relativa a la protección especial que merecen los consumidores como parte en situación de asimétrica contractual frente a los profesionales son una excepción a la regla general del domicilio del demandado ${ }^{54}$. Son foros basados en la protección especial que merece la parte débil (consumidor), que debe determinarse a la luz de la naturaleza jurídica del contrato y la identidad de las partes como consumidor frente a un profesional. Una excepción que no permite una interpretación extensiva de los conceptos autónomos de este foro para su aplicación. En la misma línea que la interpretación que debe hacerse de los conceptos autónomos del foro especial de obligaciones contractuales. Estos conceptos son: "contrato de consumo", "consumidor", y "cocontratante". Unos conceptos que ya se ha considerado en el epígrafe I como poco concisos o incluso ambiguos.

25. Ahora bien, que estos foros sean una excepción a la regla general no significa que no sigan cómo todo el sistema de foros del Reglamento Bruselas I / I bis, el "principio de previsibilidad", con-

\footnotetext{
${ }^{49}$ STJUE Air Scandinavia, FD.64.

${ }^{50}$ Conclusiones del Abogado General, sr. Henrik Saugmandsgaard ØE, párrafo 47; STJUE de 28 de enero de 2015, Harald Kolassa c. Barclays Bank Plc, C-375/13 (ECLI:EU:C:2015:37), FD.32.

${ }^{51}$ STJUE Armin Maletic, Marianne Maletic y lastminute.com GmbH, tui Österreich GmbH, de 14 de noviembre de 2013, C-478/12 (ECLI:EU:C:2013:373).

52 STJUE Air Scandinavia, FD. 59.

${ }^{53}$ STJUE Maletic, FD. 29; J. I. PARedez Pérez, "La internacionaldiad del contrato de consumo en el Reglamento Bruselas I: Comentario a la STJUE de 14 de noviembre de 2013, Asunto C-478/2012, Maletic lasminute.com GmbH", La Ley Unión Europa, No 17, 2014, pp. 28-40, esp. p. 33; J.M. VelÁzQUEz GARDETA, "El actual Reglamento 1215/2012 (Bruselas I bis) y la protección del consumidor on-line. ¿Una oportunidad perdida?”, Revista de Direito do Consumidor (RDC), No101, 2015, pp. 299-320, pp. 313-315; B. DE Groote, "Maletic and EU Jurisdiction rules for consumer contracts. How a seemingly holiday contract turns out to be international", EuCML, Vol. 5, No3, pp, 138-144.

${ }^{54}$ Vid. A-L., Calvo Caravaca y J. Carrascosa González, Derecho Internacional..., op.cit. , p. 1104; A-L., Calvo Caravaca, J. Carrascosa González Y J.V.Almuní Cid, "Capítulo 11: Contratos internacionales de consumo: Competencia judicial y ley aplicable”, en M. YzQuierdo Tolsada (Dir.), Contratos civiles, mercantiles..., op.cit., t. XVI, 2014, pp.777-848; E. CAsTEllanos Ruiz, Régimen jurídico de los consumidores: Competencia judicial internacional y ley aplicable, Comares, 2010;
} 
templado en el Cdo.11. También deben aplicarse respetando el principio útil (effect utile) y de seguridad jurídica del Reglamento Bruselas I/ I bis.

En los mismos, el objetivo de previsibilidad se cumple en el hecho que, aunque el consumidor pueda demandar y ser demandado ante su domicilio, esto es, que se permite la realización de un forum actoris totalmente justificado, -un favor o presunción más favorable "al consumidor" o favor laesi-, queda compensado para los profesionales tanto como demandados o demandantes con la aplicación estricta e interpretación restrictiva de los requisitos de aplicación material del art. 15/art. 17 del Reglamento Bruselas I/I $b i s^{55}$.

26. Estos requisitos se tienen entonces que respetar de forma cumulativa en todos los casos. De forma que si no se da alguno de los tres, como establece la jurisprudencia del TJUE, no se puede basar ni justificar la competencia judicial internacional del tribunal ante el que se plantean las acciones en los mismos ${ }^{56}$.

(i) Una de las dos partes debe tener la condición de consumidor, tal cual está definida en el Reglamento Bruselas I. Un concepto que se debe poner en relación con lo interpretado con el siguiente concepto europeo y requisito, el "contrato de consumo" 57.

(ii) Que el contrato que media entre el consumidor y el profesional haya sido efectivamenteválidamente celebrado. Un contrato que se valora por su naturaleza y finalidad. Para saber si ha sido válidamente "celebrado" no cabe valorar la situación jurídica subjetiva del "consumidor" frente al profesional, sino la existencia del contrato de consumo que vincule mediante sus cláusulas a los contratantes del consumidor con una finalidad distinta a la de un uso profesional del servicio o producto contratado por el consumidor ${ }^{58}$. Con ello, la acción queda indisociablemente vinculada al contrato considerado de "consumo" 59 .

(iii) Que este contrato esté comprendido en los contratos que el mismo artículo 15/17 contiene en su apartado $1^{\circ}$, de las letras a, a la c ${ }^{60}$.

${ }^{55}$ STJCE Rudolf Gabriel, de 11 de julio de 2002, C-96/00 (ECLI:EU:C:2001:690), párr. 57; STJUE AU Reliantco Investments LTD., y Reliantco Investments LTD Limassol Sucursala Bucuresti, de 7 de abril de 2020, C-500/18 (ECLI:EU:C:2020:264), FD. 60 (sobre la prevención de multiplicidad de tribunales) y FD. 61, 62, 63 y 64. Un favor laesi que en foros especiales por razón de la materia, no se justificaría de ninguna forma para no quebrar el principio de Derecho procesal de "igualdad de las partes"; J. CARRASCOSA GonZÁLEZ, "El foro general del domicilio del demandado y Reglamento Bruselas "I-BIS 1215/2012". Análisis crítico de la regla actor sequitur forum rei”, CDT, 2019, Vol. 11, Nº1, pp. 112-138, esp. pp. 118-119; A-L., CALVo CARAVACA Y J. CARRASCOSA GonzÁlez, Derecho International..., vol. I, op.cit p. 164; P. MANKowski y P. Nielsen, "Jurisdiction over Consumer Contracts" en U. Magnus y P. Mankowski (eds.), European Commentaries on Private International..., p. 511; P. Maestre CASAS, "El pasajero aéreo desprotegido: Obstáculos a la tutela judicial ..”, loc.cit., p. 296 : “(...) a un consumidor que se le exija litigar en el extranjero se le está disuadiendo de litigar en el extranjero" y esp. p. 302; Sobre la justificación del principio del favor laesi y el forum actoris en estos foros de protección especial; E. Fernández MASÍA, "Contratos de consumo y Competencia judicial internacional en el Reglamento 44/2001”, Estudios de Consumo, 2002, pp. 10-37, esp. p. 27; en general, sobre el favor laesi, G.J. SCHÖTZ, "El favor debilis como principio general del Derecho Internacional Privado. Su particular aplicación a las relaciones de consumo transfronterizas", Ars Iuris Salmanticensis, ESTUDIOS, Vol.1, 2013, pp. 115-150; C. WoLF, "Jurisdiction over subrogated consumer contracts", 2017, disponible en:https://papers.ssrn.com/sol3/papers.cfm?abstract_id=3043393

${ }^{56}$ STJUE Air Scandinavia, FD. 56; F.J. Garcimartín AlfÉrez, Derecho Internacional ..., op.cit., p.127.

${ }^{57}$ STJUE AU Reliantco Investments LTD., y Reliantco Investments LTD Limassol Sucursala Bucuresti, de 7 de abril de 2020, C-500/18 (ECLI:EU:C:2020:264), FD. 47.

${ }^{58}$ El controvertido concepto de "consumidor" establecido en el Reglamento Bruselas I / I bis, en la jurisprudencia del TJUE, ya desde asuntos como STJCE Rudolf Gabriel, de 11 de julio de 2002, C-96/00 (ECLI:EU:C:2001:690); STJUE Maximilian Schrems c. Facebook Ireland Ltd., de 25 de enero de 2018, C-498/16 (ECLI:EU:C:2018/17), párr. 45 y 46 (objetivo de previsibilidad); STJUE Harold Kolassa c. Barclays Bank, de 28 de enero de 2015, C-375/14 (ECLI:EU:C:2015:37), FD. 32 y 33; (sobre el concepto de consumidor en los artículos 17 y 18 y su interpretación restrictiva); STJUE Jana Pretuchová c. FIBO Group Holdings Limited, de 3 octubre de 2019, C-208/18 (ECLI:EU:C:2019:285); STJUE AU Reliantco Investments LTD., y Reliantco Investments LTD Limassol Sucursala Bucuresti, de 7 de abril de 2020, C-500/18 (ECLI:EU:C:2020:264).

${ }_{59}$ STJUE AU Reliantco Investments LTD. y Reliantco Investments LTD Limassol Sucursala Bucuresti, de 7 de abril de 2020, C-500/18 (ECLI:EU:C:2020:264), FD. 48, 49, 60 y 64, especialmente, cuando el mismo título de la Sección $4^{\circ}$, capítulo II, dice claramente "de los contratos celebrados por los consumidores"; STJUE Renate Ilsinger c. Martin Dreschers, 14 de mayo de 2009, C-180/06 (ECLI:EU:C:2009:303), FD. 52, 53, у 54.

${ }^{60}$ STJUE AU Reliantco Investments LTD. y Reliantco Investments LTD Limassol Sucursala Bucuresti, de 7 de abril de 2020, C-500/18 (ECLI:EU:C:2020:264), párr. 45 (sobre los requisitos dados en el artículo 17 RBI bis). 
27. En el asunto Air Scandinavia, el TJUE considera que no se puede aplicar finalmente el foro de protección especial de contratos celebrados por consumidores. La sra. Králová y la obligación contractual que le une con el transportista no cumple con estos requisitos cumulativos del artículo 15/17. Sin embargo, no niega que si pudiera aplicarse frente a la Agencia de viajes con quien si celebró el contrato incluido en la lista y frente a la que sí tiene una condición de consumidora ${ }^{61}$.

\section{Las cuestiones de Derecho sustantivo}

\section{Tercera cuestión prejudicial: Relación entre los derechos establecidos en el Reglamento 261/2004, la Directiva 90/314/CEE y el Reglamento Bruselas I}

27. Una vez determinado por el tribunal nacional donde se plantea la acción, que es el tribunal competente para conocer de la misma, quedan por establecer dos aspectos de máxima relevancia: (i) si tienen cabida las acciones, como las de compensación, que se solicitaban en Air Scandinavia, y (ii) la legitimidad pasiva del demandado ${ }^{62}$. En este supuesto, la cuestión clave era la relación correcta con el Reglamento Bruselas I, con el Reglamento 261/2004 o la Directiva 90/31463.

28. Según el Abogado General, este supuesto presentaba estos problemas de delimitación en la aplicación del instrumento jurídico, en ambos problemas, por sus particularidades.

Primero, por ser el vuelo un billete incluido en el pack del viaje combinado había que tomar en consideración si la Directiva 90/314/CEE en relación con el Reglamento Bruselas I. Segundo, con lo dispuesto en el Reglamento 261/2004, para dilucidar no sólo el problema de las acciones de compensación sino como se anunció en otros apartados, el de la legitimidad pasiva del transportista aéreo que no tiene ningún contrato celebrado con el pasajero ${ }^{64}$. Ambos instrumentos eran los específicos por razón de la materia de las acciones interpuestas por la pasajera contra el operador aéreo danés. Por lo que determinarían la ley sustantiva al fondo del asunto y las cuestiones arriba reseñadas. Para ello, invoca cierta jurisprudencia anterior del TJUE, el asunto Aegean Airlines en la que el TJUE ya había delimitado la aplicación de ambos instrumentos en estas cuestiones ${ }^{65}$.

\section{Opinión del TJUE sobre la tercera cuestión prejudicial: "todos para uno y uno para todos, pero con reservas"}

29. Cuando se ha analizado el foro especial por razón de la materia se ha relacionado ya con el Reglamento 261/2004, para saber si la compañía aérea que no tiene un contrato celebrado con el consumidor es igualmente considerada como un prestador de servicios que tiene obligaciones con el pasajero.

\footnotetext{
${ }^{61}$ STJUE Air Scandinavia, FD. 65.

${ }^{62}$ Vid. P. Mankowsky, Research Handbook on the Brussels I bis Regulation, Research Handbooks in European Law, 2020.

${ }^{63}$ E. Alvárez Armas y M. Dechamps, "Le droit international privé et la protection des passagers : l'articulation des sources...”, loc.cit., esp. p. 769 ; Comunicación de la Comisión, "Directrices interpretativas del Reglamento (CE) no 261/2004 del Parlamento Europeo y del Consejo por el que se establecen normas comunes sobre compensación y asistencia a pasajeros aéreos en caso de denegación de embarque y de cancelación o gran retraso de los vuelos y se deroga el Reglamento (CE) $\mathrm{n}^{\circ}$. 2027/97 del Consejo sobre responsabilidad de las compañías aéreas en caso de accidente, en su versión modificada por el Reglamento (CE) no889/2002 del Parlamento Europeo y del Consejo, DOUE, 2016/C 214/04, esp. punto 8.1.

${ }^{64}$ B. Ferrer TAPIA, El contrato áereo de pasajeros..., op.cit., pp. 310 y ss.; Z. S. TANG, Electronic Consumer Contracts in the Conflict of... op.cit. ; D. PÉrez Millán, « Función de legitimación y necesidad del documento para el ejercicio del derecho del transporte", en F. Martínez Sanz, M. V. Petit Lavall (Dirs.), Achim Putz y L. Sales Pallarés (Coords.), Aspectos jurídicos y ecónomicos del transporte. Hacia un transporte más seguro, sostenible y eficiente, Universitat Jaume I, Col.lecció "Estudis jurídics", Nº15, t. 1, 2007, pp. 709-723.

${ }^{65}$ Cómo destaca el Abogado General, sr. Henrik Saugmandsgaard ØE, p. 65, también fue planteada la misma cuestión prejudicial en la STJUE de 10 de julio de 2019, HQ \& Others, c. Aegean Airlines, C-163/18 (ECLI:EU:C:2019:585); N. PARKINSON, "HQ \& Others, c. Aegean Airlines SA (C-163/18). A commentary”, TLQ, 2019, pp. 47-52.
} 
30. No obstante, volviendo a que el vuelo pertenecía a un viaje combinado el TJUE, considera que es necesario para determinar la articulación de los derechos concedidos en el Reglamento 261/2004, la interpretación de sus disposiciones con el artículo 5 de la Directiva 90/314. Este artículo establece que tanto el organizador del viaje como el prestador del servicio que este organizador contrata para el consumidor, responden del buen cumplimiento de las obligaciones derivadas de dicho contrato. Por ello, la sra. Králová y en la misma forma que sucedió en el asunto Aegean Airlines, tiene derecho también a solicitar compensación a la Agencia de viajes. Sin embargo, con ciertas reservas de aplicación, dado que las sanciones establecidas en ambos instrumentos jurídicos pueden solaparse.

31. Las reservas vienen dadas porque las soluciones que se establecen en ambos instrumentos no son requisitos cumulativos ${ }^{66}$. El TJUE entiende que el legislador europeo no tuvo la intención de excluir a los pasajeros que contrataron el vuelo a una Agencia como parte de un pack de viaje combinado ${ }^{67}$, de solicitar por separado a la compañía aérea la compensación debida. Pero si sólo demanda al operador y buscando la compensación que no el reembolso, debe hacerlo según el artículo 6 y 7 del Reglamento 261/2004, dado que en la Directiva no se establecen las acciones de compensación que le incumben únicamente al transportista aéreo. Haya o no celebrado contrato con el pasajero ${ }^{68}$. Evitando una posible doble sanción al operador aéreo ${ }^{69}$.

En este caso, la pasajera había demandado sólo a la compañía aérea por compensación a tanto alzado. Por ello, la invocación de los artículos 6 y 7 del Reglamento 261/2004 era la correcta. Si hubiera solicitado el reembolso completo a la Agencia de viajes, el artículo 8 del Reglamento 261/2004 sí hace diferenciación y habría que ponerlo en conexión con el artículo precitado en el caso de la Directiva 90/314.

\section{Conclusiones}

33. En esta sentencia, el TJUE no se ha alejado de la jurisprudencia anterior. Ni en las cuestiones relativas a la interpretación del foro de protección especial de contratos celebrados por consumidores. $\mathrm{Ni}$ en la interpretación del foro especial por razón de la materia de la obligación contractual. Basando su respuesta en razones de proximidad y previsibilidad. Tampoco se ha alejado en las cuestiones de Derecho sustantivo en relación con el Reglamento 261/2004 y la Directiva 90/314, para determinar la legitimidad pasiva del transportista y la pertinencia de las acciones de compensación.

34. Primero. Sobre la aplicación del foro especial de la obligación contractual como "prestación de servicios" en este tipo de relaciones entre pasajeros y transportistas cuando no media contrato celebrado entre ambos. El foro especial de la obligación "contractual" no exige que medie entre las partes un contrato válidamente celebrado. Lo que se exige es que exista y se pueda identificar

${ }^{66}$ Vid. S. Rodrigues, "Air transport: The Court of Justice of the European Union Rules that the two European Compensation Regimes in case of Annulment of a Flight Forming Part of a Package Tour Are Not Cummulative (Aegean Airlines)", Concurrence (Antitrust Publications and Events)s, No 4, 10 de julio de 2019, disponible en: https://www.concurrences.com/en/ review/issues/no-4-2019/case-comments/air-transport-the-court-of-justice-of-the-european-union-rules-that-the-two

${ }^{67}$ Cf. STJUE Air Scandinavia FD. 36.

${ }^{68}$ Comunicación de la Comisión, "Directrices interpretativas del Reglamento (CE) no 261/2004 del Parlamento Europeo y del Consejo por el que se establecen normas comunes sobre compensación y asistencia a pasajeros aéreos en caso de denegación de embarque ...", cit., esp., punto 2.2.6: "Ámbito del Reglamento en relación con la Directiva sobre viajes combinados"; A. Escudié y G. Della Malva, "La responsabilité de l'Agence de Tourisme en cas de retard ou d'annulation de vol”, Village de la Justice, 7 de abril 2020, disponible en: https://www.village-justice.com/articles/responsabilite-agence-tourisme-cas-retardannulation-vol-par-anais-escudie,34580.html; del reparto de responsabilidades entre el transportista y el tercero que tiene la relación contractual directa con el pasajero, Comisión Europea, "Comunicación de la Comisión al Parlamento Europeo y al Consejo. Perspectiva europea sobre los pasajeros. Comunicación sobre los derechos de los pasajeros en todos los modos de transporte", COM (2011), 898 final, p. 12.

${ }^{69}$ De esta forma no se sobreprotege al pasajero frente a la compañía aérea, cómo interpreta el TJUE en su sentencia Aegean Airlines; J. A. LuZACK, "Avoiding double claims at all cost- AG Saugmandsgaard ØE in Aegean Airlines (C-163/18)", Recent Developments in European Consumer Law, 30 de marzo de 2019, disponible en: http://recent-ecl.blogspot.com/2019/03/ avoiding-double-claims-at-all-cost-ag.html 
una obligación de tipo contractual en función del lugar en el que dicha obligación debe ser cumplida. Como se desprende del asunto Flighright, en contratos de transporte aéreo, tanto en lugar de salida como el de llegada de los vuelos son dichos lugares de cumplimiento en los que es previsible que se puedan establecer acciones transfonterizas contra el operador aéreo. Así como también cumplen con el objetivo de proximidad entre los hechos y el tribunal que debe conocer de estas acciones.

Este foro debe ser aplicado en supuestos en los que la obligación/prestación del servicio que liga a un transportista aéreo y un pasajero haya nacido del contrato que el pasajero realiza con un tercero que le vende la prestación del servicio, incluyendo aquellos que se han vendido en un pack de "viaje combinado". Sigue existiendo la obligación de prestar un servicio a la luz del Derecho sustantivo aplicable al asunto, el Reglamento 261/2004.

35. Segundo. Del foro de protección especial en contratos celebrados con consumidores en pack de viaje combinado, pero en donde no se solicita compensación por incumplimiento a la Agencia de viajes que sí celebra el contrato con el consumidor. El foro de protección especial no puede aplicarse para demandar al transportista aéreo ni siquiera en el caso de demandar a la Agencia de viajes por el incumplimiento de éste. Debe existir un contrato válidamente celebrado con ambos contratantes del consumidor de forma indisociable, como se desprende del asunto Maletic para poder aplicar el mismo foro a contratos de consumo no excluidos de la lista de este foro que ofrece el Reglamento.

La justificación se encuentra en la interpretación restrictiva de los conceptos del artículo 15 /17 Reglamento Bruselas I / Ibis. A diferencia del foro especial por razón de la materia de la obligación contractual, es requisito cumulativo sine qua non para su aplicación, la "celebración de un contrato" con el consumidor que está unida a la acción del demandante que a su vez debe ser considerado consumidor. En los contratos de transporte, el consumidor no se considera consumidor, dada la exclusión que hace el Reglamento de estos de este foro.

36. Tercero. De la legitimidad pasiva del transportista aéreo, a la luz del Reglamento 261/2004. La legitimidad pasiva del transportista aéreo al existir obligación contractual frente al pasajero debe determinarse de conformidad con el Reglamento 261/2004, siendo la lex causae aplicable al fondo del asunto. No debe hacerse en supuestos como éste de conformidad con la Directiva 90/31, porque no se demandó a la Agencia de viajes, el único contratante de la consumidora. Esto es así porque el Reglamento 261/2004, como se esclareció en el asunto Aegean Airlines, impide que haya doble sanciones. Dependiendo a quien se demande y cuales sean las acciones que interponen los pasajeros afectados por sus incumplimientos, tengan contrato celebrado con los transportistas o el vuelo se incluya en un pack de viaje combinado tal cual está definido en la Directiva 90/314, se aplicará una disposición u otra.

37. Cuarto. Se considera que todas estas soluciones merecen una revisión futura en los foros de protección especial establecidos en el Reglamento Bruselas Ibis. Esto supondría una revisión de los conceptos de "consumidor" en estos foros incluyendo a los pasajeros. Y de los "contratos de transporte" que celebran frente a las compañías aéreas como contratos de consumo celebrados por consumidores.

Los pasajeros, -como consumidores que son en el Derecho sustantivo de consumo-, no se van a encontrar nunca en situación de igualdad de condiciones frente a los transportistas aéreos. Hayan celebrado o no un contrato con ellos o a través de un intermediario. Aplicar el foro especial por razón de la materia en obligaciones de tipo contractual es dejarles en igualdad de condiciones frente a los mismos. Una igualdad que no tienen reconocida en este Derecho sustantivo de consumo, ni en instrumentos de corte internacional o europeo que rigen el fondo de estos asuntos. 